\title{
Calcified congenital arachnoid cyst with heterotopic neuroglia in wall
}

\author{
S A M R U A Y S H U A N G S H O T I \\ From the Department of Pathology, Faculty of Medicine, Chulalongkorn University, Bangkok, \\ Thailand
}

SUMMARY Two unique findings, advanced calcification and ectopic neuroglia, were encountered in the wall of a giant congenital arachnoid cyst occurring in a 40 year old woman. The cyst almost totally filled the supratentorial subdural space of the left hemicranial cavity, was not connected with the subarachnoid space, and thus developed intra-arachnoidally. Its congenitally derived nature was supported by the unique finding of heterotopic neuroglia in the wall. Congenital arachnoid cyst must be distinguished from various cystic lesions within the central nervous system, including the neuroepithelial cyst which can arise throughout the neuraxis. It is suggested that pathogenesis of the congenital arachnoid cyst is related to aberrant flow of the ventricular cerebrospinal fluid into the developing leptomenin $x$ in the process of differentiation of the subarachnoid space. The tract or pouch may occur within the arachnoid mater, and the cyst is formed intra-arachnoidally when the former filled with fluid is closed off from the subarachnoid space.

Arachnoid cyst is rare within the cranium. Only four cysts were found among 1028 intracranial tumours in Thailand reported by Shuangshoti and Panyathanya (1974), a proportion of about $0.4 \%$ of intracranial neoplasms. We subsequently encountered an additional example of extensively calcified intracranial arachnoid cyst with ectopic neuroglia in the wall. As no reports could be traced in the medical literature of calcified arachnoid cyst and as ectopic neuroglia was present in the cyst wall, the case is reported as unique.

\section{Case report}

A 40 year old woman was admitted to hospital in coma. According to her son, she had had fever for four days before admission. Two days later, she complained of headache, dyspnoea, and pain in the chest. Subsequently, consciousness had deteriorated, and eventually she became comatose. The patient had had occasional headache in the past. There was no history of cranial trauma.

On admission, her body temperature was $38.5^{\circ} \mathrm{C}$ pulse rate $140 / \mathrm{min}$, respiratory rate $40 / \mathrm{min}$, and

Address for reprint requests: Dr Samruay Shuangshoti, Department of Pathology, Faculty of Medicine, Chulalongkorn University. Chulalongkorn Hospital, Bangkok 5, Thailand.

Accepted 26 August 1977 blood pressure $110 / 60 \mathrm{mmHg}$. The patient responded only to deep painful stimulation. Theog neck was stiff. There was bilateral papilloedema. With painful stimulation, right hemiparesis was detected. The plantar responses were extensor bilaterally. There was pulmonary crepitation. The edge of the liver was three fingerbreadths below the costal margin.

The peripheral blood had a haemoglobin concentration of $12.2 \mathrm{~g} / \mathrm{dl}$, and 20800 leucocytes/ $\mathrm{mm}^{3}$ with $96 \%$ neutrophils, $3 \%$ lymphocytes, and $1 \%$ monocytes. The urine contained sugar ( + to ++++ ). Blood chemical studies produced the following findings: urea nitrogen $20 \mathrm{mmol} / 1$ (56 $\mathrm{mg} / \mathrm{dl})$, sugar $7.16-22.2 \mathrm{mmol} / 1(129-400 \mathrm{mg} / \mathrm{dl})$, sodium $114-132 \mathrm{mmol} / 1$, potassium $2.3-4.5 \mathrm{mmol}$ $/ 1$, and carbon dioxide $10-13 \mathrm{mmol} / 1$. Glycosuria and hyperglycaemia were related to intravenous infusion of the solution of glucose. Blood culture showed growth of Diplococci pneumoniae. The cloudy cerebrospinal fluid (CSF) in a lumbar puncture disclosed the following values: $260 \mathrm{mmH}_{2} \mathrm{O}$ pressure, 9110 leucocytes $/ \mathrm{mm}^{3}$ with $66 \%$ neutrophils and $34 \%$ lymphocytes, and four plus Pandy's reaction. Gram-positive Diplococci were present in the CSF sediment.

A radiograph of the chest showed enlargement of the cardiac shadow and pulmonary infiltration. Plain film of the skull disclosed enlargement and 
thinning of the left hemicranium, especially the vault, in comparison to the right. Linear calcification was seen below the inner table of the left cranial vault. Bilateral carotid angiography gave evidence of an avascular lesion in the left temporal region. Tapping of the suspected lesion through a hole made with a hand drill in the left temporal bone yielded bloody fluid, presumably traumatic, under pressure of $100 \mathrm{mmH}_{2} \mathrm{O}$. The patient died in deep coma two days after admission, despite penicillin and other supportive treatments.

\section{NECROPSY}

The general findings were portal cirrhosis of the liver, bilateral acute purulent pleuritis, bronchitis, pericarditis, gastromalacia, multiple small acute ulcers of the stomach and duodenum, and altered blood throughout the digestive tract $(1000 \mathrm{ml})$. The kidneys were unremarkable.

The brain weighed $1170 \mathrm{~g}$. A unilocular, partially calcified cyst filled the left half of the supra- tentorial subdural space from the frontal to the occipital poles (Fig. 1). It had an egg shell appearance and entirely covered the dorsal and lateral surfaces of the left cerebral hemisphere, including the basal aspect of the left temporal lobe. The overlying dura mater could be peeled easily from the dorsal and lateral surfaces of the cyst, but was firmly attached to the severely calcified cyst wall at the temporal region. The medial wall of the cyst lay against the falx cerebri. The expanded rostral portion of the cyst compressed the atrophic frontal and temporal lobes of the left cerebrum. The cyst measured $180 \mathrm{~mm}$ rostrocaudally, $80 \mathrm{~mm}$ at the expanded rostral half, and $20 \mathrm{~mm}$ at the partially collapsed caudal half. It was partly filled by about $30 \mathrm{ml}$ of thin strawcoloured fluid mixed with about $10 \mathrm{ml}$ of recent blood clot. The cyst did not communicate with the subarachnoid space or the ventricular system of the brain.

The leptomeninges on the dorsum of the brain were covered by films of fibrinopurulent exudate.

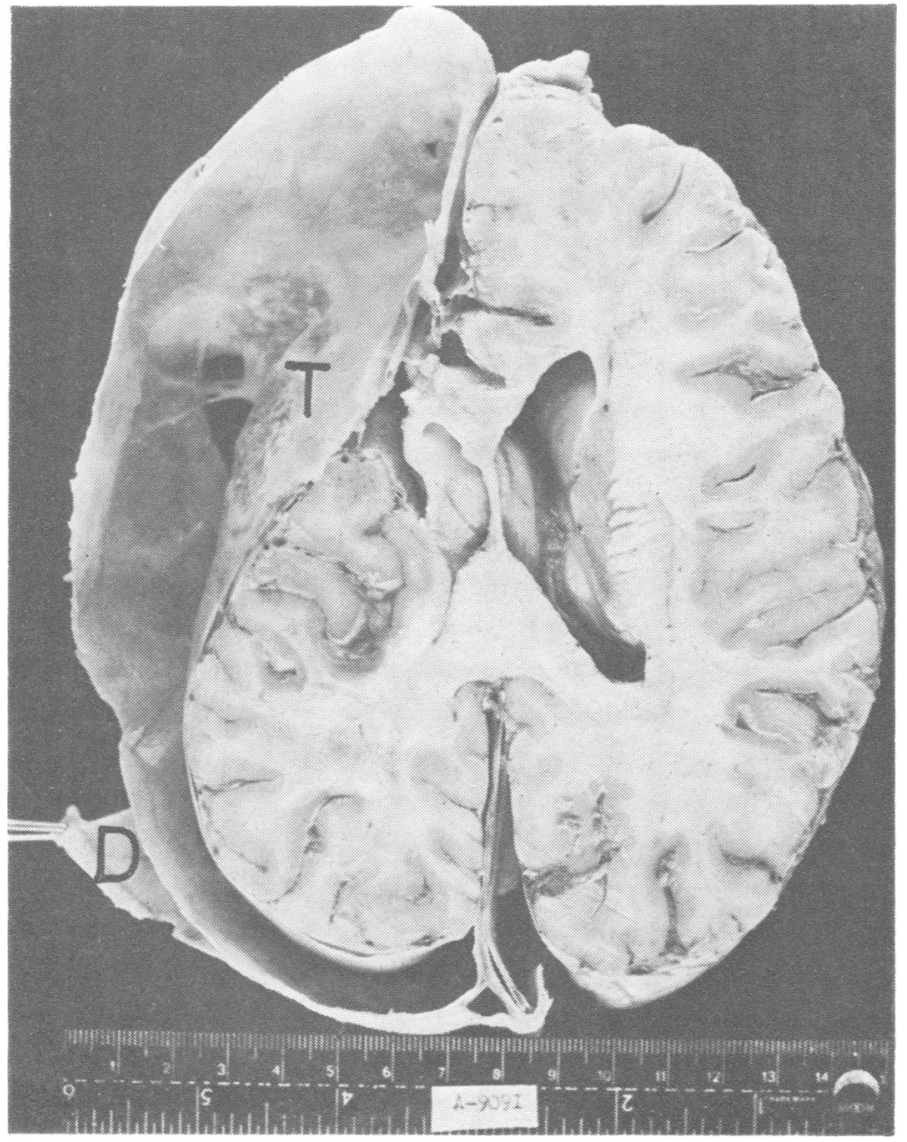

Fig. 1 Horizontally sectioned brain showing ventral portion of the arachnoid cyst in the left half of the subdural space. $D$ indicates the dura mater on the lateral aspect of the cyst. The cyst wall is extensively calcified in the temporal region $(T)$ which is perforated in the postmortem removal because of the firm adhesions with the dura mater lining the middle cranial fossa. Note atrophic left cerebral hemisphere and collapsed left lateral ventricle. 
Blood vessels in the subarachnoid space and cerebral substance were considerably congested. The left lateral ventricle was small, especially the frontal and temporal horns.

Specimens of decalcified cyst wall were embedded in paraffin, and stained with haematoxylin and eosin (H and $\mathbf{E})$, Gomori's reticulum, Gomori's iron, and Masson's trichrome stains.

Microscopically (Figs. 2 and 3), the cyst wall consisted of collagen and reticulin fibres which were severely hyalinised, calcified (Fig. 2A), and interspersed by occasional islands of meningocytes (Fig. 2B), a few psammoma bodies (Fig. 2C), and neuroglia with numerous processes (Figs. 2C and 3). The neuroglia was found only in the section taken from the medial wall of the cyst lying towards the left cerebral hemisphere. Reticulin fibres were frequently found in the meningocytic cluster, but were absent in the neuroglial island.
Haemosiderin and inflammatory cells of chronic variety were not seen (Fig. 2A). However, the medial wall of the cyst was infiltrated by many neutrophils in association with widespread acute purulent meningitis. The cyst wall did not have epithelium either on the inner or outer surface.

\section{COMMENT}

The diagnosis was giant supratentorial congenital arachnoid cyst with advanced calcification and ectopic neuroglia in the wall. Death of the patient was attributed to portal cirrhosis of the liver, acute purulent inflammation of the pleura, pericardium, and leptomeninges, with superimposed haemorrhage of the upper alimentary tract. An intracranial lesion is occasionally associated with acute ulceration and malacia with bleeding of the upper digestive tract (Watson and Netsky, 1954). Raised blood urea nitrogen was suggested to be

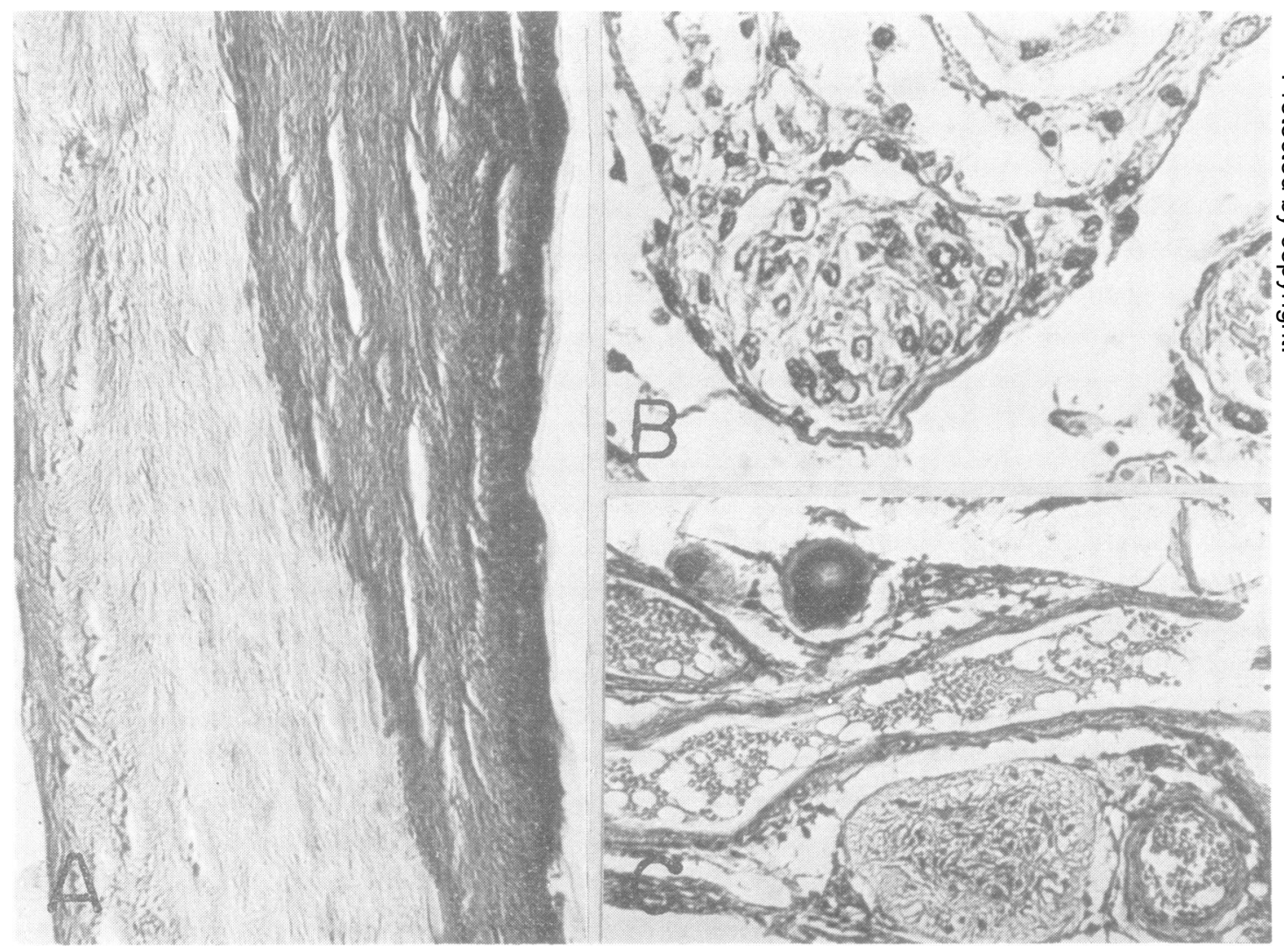

Fig. 2 Histopathological features of the cyst wall. A-the severely hyalinised and calcified fibrous wall is devoid of chronic inflammation, haemosiderin, and epithelium $(H \& E \times 100) ; B-a$ whorl of meningocytes is illustrated $(H \& E \times 400) ; C-$ two psammoma bodies, a focus of neuroglial heterotopia, and blood vessels are demonstrated $(H \& E \times 100)$. 
related to alimentary azotaemia which frequently occurs to some extent in severe haemorrhage from the upper gastrointestinal canal (Palmer, 1963).

\section{Discussion}

Meningocytes are normally disseminated throughout the arachnoid mater, and have also been called arachnoid cells, meningoblasts, mesothelial, meningothelial, endothelial cells, and modified or specialised fibroblasts (Globus, 1937; Shuangshoti and Netsky, 1966a, 1970; Netsky and Shuangshoti, 1975). Psammoma bodies are as well scattered in the arachnoid mater as in the glomus choroideum (Shuangshoti and Netsky, 1970). The mode of formation of these calcospherites has been debated, but it has been suggested that they are related to the calcification occurring in degenerated meningocytic whorls (Shuangshoti and Netsky, 1970). The presence of meningocytes and psammoma bodies indicates that the cyst of our case is arachnoidal in origin.
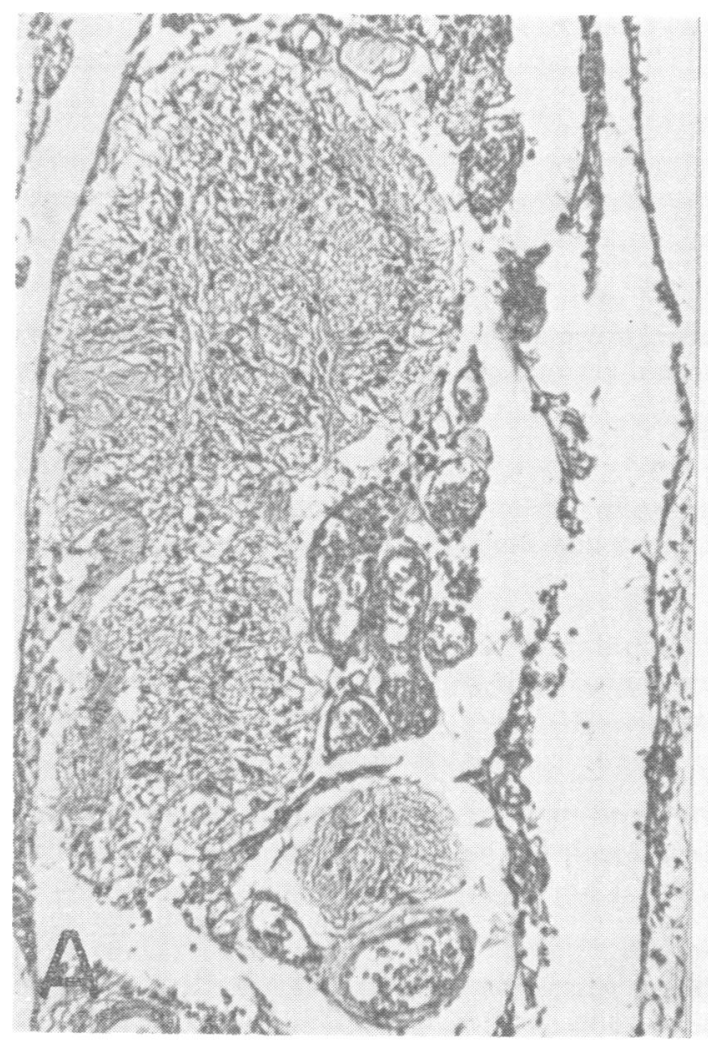

Cyst of the arachnoid may be congenital or acquired. The acquired arachnoid cysts may occur after cranial trauma, intracranial haemorrhage, or inflammation which result in localised entrapment of the CSF because of adhesions between the pia mater and arachnoid mater, or are related to herniation of the arachnoid mater through dural or cranial defects (Soule and Whitcomb, 1946; Taveras and Ranshoff, 1953; Starkman et al., 1958). Moreover, an old subdural haematoma may become cystic especially when the large clot is partly absorbed; a subdural cyst with inner and outer neomembranes is formed and may be calcified (Merritt, 1973). The lack of a history of cranial trauma and the finding of haemosiderin and chronic inflammation in the cyst wall of our patient strongly suggests that the cyst was not formed secondarily.

It is also unlikely that the cyst was porencephalic, because connection was absent between its cavity and the ventricular system or subarachnoid space of the brain. Nevertheless, the present

Fig. 3 Ectopic neuroglia within the cyst wall. A-two circumscribed areas of neuroglial heterotopia are surrounded by thin layers of vascularised connective tissue $(H \& E \times 100)$, B-neuroglia with distinctive processes from the larger island in $A(H \& E \times 400)$. 
cyst must be differentiated from the neuroepithelial (colloid) cyst which is mostly derived congenitally (Shuangshoti and Netsky, 1966a, b; Shuangshoti, 1975; Shuangshoti et al., 1977), may be located in the subdural space (List and Williams, 1961), and may contain meningocytes, psammoma bodies, and neuroglia in its wall (Aicardi, 1975; Shuangshoti et al., 1977). Indeed occasional neuroepithelial cysts have been interpreted as arachnoid cysts. For example, Zehnder (1938) reported a large subarachnoid cyst arising in the right lateral fissure of the brain of an adult man. Its wall consisted of leptomeninges with an inner lining of ciliated cubic and cylindrical epithelium. Zehnder (1938) regarded this cyst as similar to "cyst of the foramen of Monro (colloid cyst)", but Starkman et al. (1958) considered it to be an arachnoid cyst. Shuangshoti (1975) and Shuangshoti et al. (1975) interpreted the same lesion (Zehnder, 1938) as a neuroepithelial cyst. Hoffmann (1960) reported a child with quadriplegia because of compression on the anterior surface of the cervical segment of the spinal cord by an "arachnoidal cyst". The thin fibrous cyst wall had an inner lining of "meningothelial cells of low cuboidal type". Shuangshoti (1975) and Netsky and Shuangshoti (1975) agreed with Moore and Book (1966) that the lining of the cyst was ependymal, and that the cyst was neuroepithelial. An infant was presented by Lewis (1962) as having an "arachnoidal cyst" in the posterior cranial fossa and obstructive hydrocephalus. The cyst was attached to the tentorium, and compressed the cerebellum near the midline. The inner surface of the fibrous wall of the cyst was lined in part by cuboidal epithelium with papillary infoldings resembling choroidal villi. Shuangshoti and Netsky (1966b) considered this cyst as neuroepithelial, and discussed the mode of occurrence of the papillary projections from the neuroepithelium lining the cyst. Harrison (1971) reported several "arachnoid cysts" occurring in children. Three cysts occupying the suprasellar and interpeduncular regions of the subarachnoid space had neuroglial walls with an inner lining of "ependyma". They were, therefore, neuroepithelial cysts (Shuangshoti et al., 1977). Nevertheless, the cyst of the present patient was not neuroepithelial because it had no epithelial lining.

We agree with Friede and Yasargil (1977), who reviewed and reported "intracerebral epithelial (ependymal) cysts", that they have sufficient characteristic features to distinguish them from arachnoid cysts. However, we do not agree with their statement that intracerebral epithelial cysts are distinguishable from intraventricular "colloid cysts", because we consider that they are the same type of lesion. "Colloid cysts" occur throughout the neuraxis including the cranial subdural and subarachnoid spaces, as well as in the cerebral substance, various ventricles, vertebral canal, and subcutaneous tissue of the back (Shuangshoti et al., 1977). A 4 year old boy reported by Shuangshoti et al. (1977) had three epithelium-lined cysts, two in the supratentorial subarachnoid space, and one in the third ventricle in association with other congenital defects of the neuraxis and eye. These authors regarded all cysts as "colloid".

The present arachnoid cyst was considered to be congenital. Asymmetry of the skull with enlarged and thinned left hemicranium in relation to the underlying cyst which had advanced calcification in its wall indicates that the cyst had been present for a considerable period of time. Moreover, the congenital nature of the cyst is supported further by the presence of ectopic neuroglia in its wall. Once neuroglia is located beyond the cortical surface of the brain, as in the arachnoid mater, it is heterotopic (Cooper and Kernohan, 1951; Popoff and Feigin, 1964).

The mode of occurrence of the congenital arachnoid cyst might be clarified by reviewing the development of the meninges and the CSF dynamics. The neural tube lined by pseudostratified neuroepithelium is enveloped by a layer of mesenchyme which lies between the underlying primitive neuraxis and the developing cartilagenous or bony tissue of the cranium. This mesenchymal layer is also known as the skeletoneural intertissue or perimedullary mesenchyme; it embodies the primordia of the meninges, periosteum of the craniospinal axis, and stroma of the choroid plexus (Globus, 1937; Shuangshoti and Netsky, 1966a; Netsky and Shuangshoti, 1975). We do not concur with Harvey and Burr (1926) in regarding the meninges as ectodermal in origin.

In an early state of differentiation, the skeletoneural intertissue splits off the periosteum of the cranium which is followed by separation of the dura mater from the leptomeninx. Development of the subarachnoid space is related to passage of CSF within the developing cerebral ventricles through the fourth ventricular outlets into the leptomeninx. The force propelling the intraventricular CSF into the latter has been thought to originate in a pump-like action from the pulse wave of the choroid plexuses which occurs when blood vessels of the plexuses are filled by blood. According to Bering $(1955,1962)$, the choroidal pump-like action has an influence in the development and patency of the developing cerebral aqueduct, outlets of the fourth ventricle, and 
subarachnoid space. It is suggested that other factors influencing the CSF circulation, such as the ependymal ciliary motion (Cathcart and Worthington, 1963), pulse wave of various cerebral arteries especially at the base of the brain (Dott and Gillingham, 1958), or some as yet unknown factors may take part in the development of the subarachnoid space. Eventually, the leptomeninx is separated and filled by the CSF to form the subarachnoid space. Mesenchyme on either side of the space is differentiated further into the pia mater and the arachnoid mater. It is likely that aberration in the flow of CSF during an early differentiation of the arachnoid mater could result in formation of the tract or pouch within the arachnoid mater which may be closed off from the subarachnoid space and entrap the fluid; the congenital arachnoid cyst is then formed intraarachnoidally.

The terms primary arachnoid. or primary congenital arachnoid, or intra-arachnoid cysts have been used for cystic lesions of the arachnoid mater which are believed to be formed congenitally (Oliver, 1958; Starkman et al., 1958; Schreiber, 1959; Ghatak and Mushrush, 1971). The term "intra-arachnoid cyst" indicates that the cyst arising in the arachnoid mater is entirely separated from the brain by the arachnoid mater and the subarachnoid space. The present cyst, therefore, can be called intra-arachnoid. However, it is suggested that the term "congenital arachnoid cyst" is clear enough in indicating its congenitally malformed nature and tissue of origin.

The author is grateful to Dr Somsak Dhechakaisaya, Professor and Head of the Department of Pathology, who gave permission to report this case.

\section{References}

Aicardi. J. (1975). Supratentorial extracerebral cysts in infants and children. Journal of Neurology. Neurosurgery. and Psychiatry, 38, 57-68.

Bering. E. A.. (1955). Choroid plexus and arterial pulsation of cerebrospinal fluid. Archives of Neurology and Psychiatry (Chicago). 73, 165-172.

Bering. E. A. (1962). Circulation of the cerebrospinal fluid: demonstration of the choroid plexuses as the generator of the force for flow of fluid and ventricular enlargement. Journal of Neurosurgery (Chicago). 19, 405-413.

Cathcart. R. S.. and Worthington, W. C. (1963). Ependymal cilia: distribution and activity in adult human brain. Science, 139, 221-222.

Cooper. I. S.. and Kernohan, J. W. (1951). Heterotopic glial nests in the subarachnoid spaces: histopathologic characteristics, mode of origin and relation to meningeal gliomas. Journal of Neuropathology and Experimental Neurology, 10, 16-29.

Dott, N. M., and Gillingham, F. J. (1958). Mechanical aspects of the cerebrospinal fluid circulation-physiological. pathological, surgical. In Ciba Foundation Symposium on The Cerebrospinal Fluid: Production, Circulation and Absorption, pp. 246261. Edited by G. W. E. Wolstenholme and C. M. O'Connor. Little, Brown and Company: Boston.

Friede, R. L., and Yasargil, M. G. (1977). Supratentorial intracerebral epithelial (ependymal) cysts: review. case reports, and fine structure. Journal of Neurology, Neurosurgery, and Psychiatry, 40, 127137.

Ghatak, N. R., and Mushrush. G. J. (1971). Supratentorial intra-arachnoid cyst: case report. Journal of Neurosurgery (Chicago). 35, 477-482.

Globus, J. H. (1937). Meningiomas: origin, divergence in structure and relationship to contiguous tissues in light of phylogenesis of the meninges, with suggestion of a simplified classification of meningeal neoplasms. Archives of Neurology and Psychiatry (Chicago), 38, 667-712.

Harrison, M. J. G. (1971). Cerebral arachnoid cysts in children. Journal of Neurology. Neurosurgery, and Psychiatry, 34, 316-323.

Harvey, S. C., and Burr. H. S. (1926). The development of the meninges. Archives of Neurology and Psychiatry (Chicago). 15, 545-567.

Hoffmann. G. T. (1960). Cervical arachnoidal cyst: report of a 6-year-old Negro male with recovery from quadriplegia. Journal of Neurosurgery (Chicago), 17, 327-330.

Lewis, A. J. (1962). Infantile hydrocephalus caused by arachnoid cyst: case report. Journal of Neurosurgery (Chicago), 19, 431-434.

List, C. F., and Williams, J. R. (1961). Subdural epithelial cyst in the interhemispheric fissure: report of a case with some remarks concerning the classification of intracranial epithelial cyst. Journal of Neurosurgery (Chicago). 18, 690-693.

Merritt. H. (1973). A Textbook of Neurology. Fifth edition. p. 327. Lea and Febiger: Philadelphia.

Moore. M. T.. and Book, M. H. (1966). Congenital cervical ependymal cyst: report of a case with symptoms precipitated by injury. Journal of Neurosurgery (Chicago), 24, 558-561.

Netsky, M. G., and Shuangshoti. S. (1975). The Choroid Plexus in Health and Disease. Pp. 3. 201217, and 277. John Wright: Bristol.

Oliver, L. C. (1958). Primary arachnoid cysts: report of two cases. British Medical Journal. 1, 1147-1149.

Palmer. E. D. (1963). Clinical Gastro-enterology. Second edition. p. 230. Harper and Row: New York.

Popoff. N.. and Feigin. I. (1964). Heterotopic central nervous tissue in subarachnoid space. Archives of Pathology (Chicago), 78, 533-539.

Schreiber. M. S. (1959). Primary congenital arachnoid cysts. Medical Journal of Australia. 2, 802-8()3.

Shuangshoti. S. (1975). Neuroepithelial cysts: first study of four cases in Thailand and review of the 
related literature. Journal of Medical Association of Thailand, 58, 413-436.

Shuangshoti, S., and Netsky, M. G. (1966a). Histogenesis of choroid plexus in man. American Journal of Anatomy, 118, 283-316.

Shuangshoti, S., and Netsky, M. G. (1966b). Neuroepithelial (colloid) cysts of the nervous system: further observations on pathogenesis, location, incidence, and histochemistry. Neurology (Minneapolis), 16, 887-903.

Shuangshoti, S., and Netsky, M. G. (1970). Human choroid plexus: morphologic and histochemical alterations with age. American Journal of Anatomy, 128, 73-96.

Shuangshoti, S., and Panyathanya, R. (1974). Neural neoplasms in Thailand: a study of 2897 cases. Neurology (Minneapolis), 24, 1127-1134.

Shuangshoti, S., Phonprasert, C., Suwanwela, N., and Netsky, M. G. (1975). Combined neuroepithelial (colloid) cyst and xanthogranuloma (xanthoma) in the third ventricle. Neurology (Minneapolis), 25, 547-552.

Shuangshoti, S., Phisitbutr, M., Kasantikul, V., and
Netsky, M. G. (1977). Multiple neuroepithelial (colloid) cysts: association with other congenital anomalies. Neurology (Minneapolis), 27, 561-566.

Soule, A. B., and Whitcomb, B. B. (1946). Extensive erosion of the base of the skull from a leptomeningeal cyst. Archives of Neurology and Psychiatry (Chicago), 55, 382-387.

Starkman, S. P., Brown, T. C., and Linell, E. A. (1958). Cerebral arachnoid cysts. Journal of Neuropathology and Experimental Neurology, 17, 484500 ,.

Taveras, J. M., and Ranshoff, J. (1953). Leptomeningeal cysts of the brain following trauma with erosion of the skull. Journal of Neurosurgery (Chicago), 10, 233-241.

Watson, J. M., and Netsky, M. G. (1954). Ulceration and malacia of the upper alimentary tract in neurologic disorclers. Archives of Neurology and Psychiatry (Chicago), 72, 426-439.

Zehnder, M. (1938). Subarachnoidalcysten des Gehirns. Zentralblatt für Neurochirurgie, 3, 100112. 